\title{
Health is Control
}

\author{
Timothy A Carey*
}

Centre for Remote Health, Flinders University and Charles Darwin University, Australia

*Corresponding author: Timothy A Carey, Prof Tim Carey, Centre for Remote Health, PO Box 4066, Alice Springs, NT 0871, Australia, Tel: +61 (0)8 8951 4700; Fax: +61 (0)8 8951 4777; E-mail: Tim.Carey@flinders.edu.au

Rec date: Dec 28, 2015; Acc date: Feb 01, 2016; Pub date: Feb 06, 2016

Copyright: (C) 2016 Carey TA. This is an open-access article distributed under the terms of the Creative Commons Attribution License, which permits unrestricted use, distribution, and reproduction in any medium, provided the original author and source are credited.

\section{Short Communication}

Definitions in health are important for a variety of reasons including helping to determine the appropriate allocation of resources. Given the burgeoning costs of health care in many countries it is critical to be clear about which people need what services at any point in time. With changing definitions of unhealthy cholesterol levels, for example, 13 million then 36 million then 40 million Americans were considered to be in need of treatment [1].

Clearly, whether treatment is needed for 13 million or 40 million people is a decision that carries many serious implications. Definitions matter. If definitions are inaccurate or imprecise, people in need of services could be left untreated, or conversely, otherwise healthy people could be subjected to needless treatment with a consequent waste of limited financial resources.

The definition of health offered by the World Health Organization (WHO) is "Health is a state of complete physical, mental and social well-being and not merely the absence of disease or infirmity." [2]. This definition has not changed since 1948. It is unlikely that anyone would be considered to be healthy according to this definition, or at least not healthy in any sustained or enduring way. Is anyone ever in a state of complete physical, mental, and social wellbeing? This definition, then, provides little guidance as to when ill health should be considered to be present. A more precise and accurate definition of health would assist in the judicious apportioning of resources including a more sophisticated and nuanced approach to national health policies and budgets.

A robust and precise definition of health should also apply cross-culturally which, in some ways, raises an interesting quandary. In Australia, the Indigenous definition of health that has been used as a standard for more than 20 years is: "Not just the physical well-being of the individual but the social, emotional, and cultural well-being of the whole community. This is a whole-of-life view and includes the cyclical concept of life-death-life" [3]. This definition is similar to the WHO definition in many respects. An examination of the document A national Aboriginal Health Strategy 1989 [3], however, reveals that this definition of health is a summarised version of a more complete definition from the previous page:
"Health" to Aboriginal peoples is a matter of determining all aspects of their life, including control over their physical environment, of dignity, of community self-esteem, and of justice. It is not merely a matter of the provision of doctors, hospitals, medicines or the absence of disease and incapacity.

Prior to colonisation Aboriginal peoples had control over all aspects of their life. They were able to exercise selfdetermination in its purest form. They were able to determine their "very-being", the nature of which ensured their psychological fulfilment and incorporated the cultural, social and spiritual sense.

In Aboriginal society there was no word, term or expression for "health" as it is understood as in Western society. It would be difficult from the Aboriginal perception to conceptualise "health" as one aspect of life. The word as it is used in Western society almost defies translation but the nearest translation in an Aboriginal context would probably be a term such as "life is health is life."

In contemporary terms Aboriginal people are more concerned about the "quality of life" Traditional

Aboriginal social systems include a three-dimensional model that provides a blue-print for living. Such a social system is based on inter-relationships between people and land, people and creator beings, and between people, which ideally stipulates inter-dependence within and between each set of relationships.

The expanded definition is instructive in a number ways. It is important to note that, traditionally, Australian Indigenous people had no word for "health" as it is understood in contemporary society. This highlights the somewhat paradoxical quandary referred to earlier. A suitable definition of health will need to be satisfactory to all people including cultural groups who may not consider health from a Western biomedical perspective. Also, as indicated in the first paragraph of the definition, "health" to the Indigenous people of Australia is inextricably linked to self-determination and control.

The definition from page ix of the National Health Strategy Working Party (1989) document provides an important clue as to where a more appropriate definition might come from. Control is a fact of nature [4] that is essential to life [5]. An entity that lives must be able to control its internal 
environment despite varying external conditions and circumstances. Control, established through the mechanism of negative feedback, has been identified at the biological, psychological, and social levels [6]. It is well accepted that control of variables such as body temperature, blood oxygen levels, and blood glucose levels are essential for life. It is perhaps less well recognised that control of variables related to psychological and social functioning are also essential to life.

In the social determinants of health, Marmot uses control and social engagement as an organising principle [7]. Given that he describes social engagement as empowerment at a community level, this construct could be considered to refer to the social aspect of control. Health from a social determinants perspective, therefore, is fundamentally about control. Marmot claims that "What is important not so much what you have but what you can do with what you have" (p. 565). Moreover, he emphasises that if people are not able to take control of their lives, if they do not have the conditions "that would allow them to live lives they would choose to live; ill health is an inevitable result" [8].

Control, then, is central to health. No, control is health. Health is control. Health is the control of important biological, psychological, and social variables.

A definition of control that is both precise and accurate is: "Achievement and maintenance of a preselected perceptual state in the controlling system, through actions on the environment that also cancel the effects of disturbances." [9] In other words, the state of the internal environment of the controlling system is created and then maintained by cancelling the effects of influences from the external environment that would otherwise disturb the internal state. A controlling system that was unable to achieve and maintain a preselected perceptual state would be considered to be in illhealth. A single cell, in order to thrive and flourish, must be able to control the state inside its membrane in the context of varying conditions outside the membrane. If the cell is unable to do this, perhaps the conditions outside the membrane overwhelm the cell's counteracting efforts, the cell will perish.

Part of the elegance of this definition is that it applies equally appropriately whether the controlling system is a single cell, an organ inside a living creature, or the entire creature itself. From a single cell to a single individual the same principle of control applies. To thrive and flourish individuals must be able to simultaneously control a range of biological, psychological, and social variables. People must be able to keep their bodies warm enough or cool enough, they must be able to keep their psychological states content enough, and they must be able to keep their social worlds engaged enough. Of course, what is "enough" will vary from individual to individual yet the process of control remains constant. III health occurs when preselected perceptual states are unable to be achieved and maintained. Fever is an inability to achieve and maintain a stable body temperature. Diabetes mellitus is an inability to achieve and maintain appropriate blood glucose levels.
Placing control at the centre of deliberations about health will have important implications for both research and practice. From a research perspective, it will be useful to investigate health problems as breakdowns in control processes. Treatments might become more precise and more potent if the underlying control processes were understood and targeted.

Depression and obesity are two major public health problems that exemplify the benefits that a shift in focus to control processes might yield. For the most part, depression is treated as a biological problem. The chemical imbalance hypothesis is still often used to explain the manifestation of depression even though there has never been any evidence for this idea [10]. Something must surely be awry when the prevalence of depression has increased a thousand fold since the introduction of antidepressants [11]. Nowhere else in medicine would this be tolerated. If a new treatment for tuberculosis was developed, for example, and it was discovered that, after widespread use of the treatment the prevalence of tuberculosis had increased a thousand fold, the treatment would quickly be abandoned. This has not happened with the pharmacological treatment of depression.

There is also evidence that antidepressant medications have their effects by disabling the negative feedback mechanism that controls neurotransmitter levels [12]. This is exactly the opposite result that would be required if health was considered from a control perspective. Medications and other interventions would be applied to augment, not retard, the natural negative feedback mechanisms in operation.

While depression is currently treated predominantly at a biological level, a shift in perspective to a "health is control" paradigm would consider depression as primarily a psychological and social problem. Control processes at the psychological and social levels would be the main targets of treatment. Indeed, conflict between control systems appears to be an accurate and parsimonious account of the manifestation of psychological distress in general including the disabling effects of trauma for some people [13]. In addition to the treatment implications, focussing on control processes will allow researchers to integrate genetic and biochemical results with psychological and social functioning for a more complete and holistic understanding [14].

With obesity, bariatric surgery is an effective treatment for some but not all patients. For example, a mean excess weight loss of $61.2 \%$ for all patients was reported in a systematic review of bariatric surgery [15]. Given the impact of obesity on other diseases such as heart disease and diabetes, and the general increase of obesity in the population, it is important to strive to improve the effectiveness of our treatments in this area. Again, approaching obesity from the perspective of control processes might assist. If someone eats excessively to achieve emotional stability, for example, it might be expected that bariatric surgery would be less effective for this person. Unless the person found other ways to achieve emotional comfort we could expect that food would still be used for this purpose. Understanding the perceptual state that is being achieved and maintained through a particular eating regime 
would allow clinicians to target treatments more strategically for greater effect.

Defining health as control would allow a more sophisticated, systematic, and nuanced approach to both research and treatment. Moreover, it would allow a clearer understanding of when ill health is occurring and would help to inform national policies and health budgets. A shift in attention to focus on the perceptual states that are being achieved and maintained is only a slight change of perspective but one that would yield maximum rewards for both clinical treatments and public health programs. "Health is control" as a new guiding principle will enable a more efficient and effective use of limited health resources resulting in unprecedented levels of health on a global scale.

\section{References}

1. Bourbon WT (1995) Perceptual control theory. In: Roitblat HL and Meyer JA (Eds). In Comparative Approaches to Cognitive Science. 151-172.

2. Buchwald $H$, Avidor $Y$, Braunwald $E$, Jensen $M D$, Pories $W$, et al. (2004) Bariatric surgery: a systematic review and meta-analysis. JAMA 292: 1724-1737.

3. Carey TA (2013) Mental health: integration is the key to the revolution. Lancet 382: 1403-1404.

4. Carey TA, Mansell W, Tai SJ (2014) A biopsychosocial mode based on negative feedback and control. Frontiers of Human Neuroscience 94: 1-10.

5. Carey TA, Mansell W, Tai SJ, Turkington D (2014) Conflicted control systems: the neural architecture of trauma. Lancet Psychiatry 1: 316-318.
6. Gotzsche P (2013) Deadly medicines and organised crime: How big pharma has corrupted healthcare. London: Radcliffe Publishing.

7. Healy D (2004) Let them eat Prozac: The unhealthy relationship between the pharmaceutical industry and depression. New York: New York University Press.

8. Marmot $M$ (2006) Health in an unequal world: social circumstances, biology and disease. Clin Med (Lond) 6: 559-572.

9. Marmot $M$ (2011) Social determinants and the health of Indigenous Australians. Med J Aust 194: 512-513.

10. Moynihan R, Cassels A (2005) Selling Sickness: How the world's biggest pharmaceutical companies are turning us all into patients. New York: Nation Books.

11. National Health Strategy Working Party (1989) A national Aboriginal health strategy 1989. Canberra, Australia: Office of Aboriginal and Torres Strait Islander Health.

12. Powers WT (1973) Behavior: The control of perception (2ndedn). New Canaan, CT: Benchmark.

13. Powers WT (2008) Living controls systems III: The fact of control. New Canaan, CT: Benchmark.

14. Preamble to the Constitution of the World Health Organization as adopted by the International Health Conference, New York, 19-22 June, 1946; signed on 22 July 1946 by the representatives of 61 States (Official Records of the World Health Organization) 2: 100 .

15. Roman MW (2012) The research basis for Robert Whitaker's "Anatomy of an epidemic: magic bullets, psychiatric drugs and the astonishing rise of mental illness in America. Issues Ment Health Nurs 33: 707-711. 